\title{
SIMPLIFIED APPROACH OF FREE VIBRATION ANALYSIS OF PLATES SUPPORTED IN VICINITY OF THE CORNERS BY BEM
}

\author{
Michat Guminiak \\ Institute of Structural Engineering, Poznan University of Technology, Poland \\ michal.guminiak@put.poznan.pl
}

\begin{abstract}
Free vibration analysis of Kirchhoff plate by the Boundary Element Method is presented in the paper. The boundary integral equation are derived according to the Bettie theorem. The collocation version of BEM with non-singular approach with one and double collocation points is used. The constant type of element is introduced. Boundary support at selected point is modelled as support in vicinity of point along single boundary element.
\end{abstract}

\section{Introduction}

Plates supported at points, in vicinity of selected points, for example by the columns, are often used in building structures. The bending problem of plates supported on boundary or rested on internal supports is the classic boundary issue in theory of plates and shells. The columns are often located on a plate edges. The first well known work included strict solutions of these problems is publication of Nadai [1]. Iguchi [2] considered free vibrations of thin plates supported at the corners. Kączkowski [3] applied double Fourier range of sines to derive a general solution of boundary problem of orthotropic rectangular plates with optional boundary conditions including internal supports located at the plate corners. Timoshenko and Woinowsky-Krieger [4] analysed a static problem of a square plate rested on supports located at the corners by. The solutions as polynominals and range of cosines were assumed. Woźnica [5] solved analytically similar static and dynamic problem using Fourier transformation.

A lot of papers present numerical approach especially the Finite Difference Method (FDM), the Finite Element Method (FEM) and the Finite Strip Method (FSM) as a useful tools in plate bending analysis. Wide review of the literature is included and cited by Guminiak and Sygulski [6]. The Boundary Element Method (BEM) was proposed as independent numerical tool for applied for engineering applications [7, 8]. Bèzine [9] and Stern [10] introduced BEM for analysis of plate bending according to Kirchhoff theory. Vander Weeën [11] proposed fundamental solutions for Reissner plate and used BEM to numerical analysis. Thick plates acoording to Reissner theory were analysed by Litewka and Sygulski [12] by the BEM. Authors applied fundamental solution derived by Ganowicz [13]. Myślecki [14, 15], Myślecki and Oleńkiewicz [16] and Oleńkiewicz [17] applied BEM tech- 
nique in the anaysis of plates and surface structures. Authors also used Kupradze approach to formulate the boundary integral equation.

Modelling of plate bending with internal plate supports requires modification of governing boundary integral equation. The most popular approach was proposed by Bèzine [18] in which the forces at the internal supports are treated as unknown variables. This techniques is also used by de Paiva and Venturini [19, 20], Hartmann and Zotemantel [21] and Abdel-Akher and Hartley [22]. Katsikadelis et al. [23], Providakis and Toungelidis [24] applied technique of Bèzine to solve dynamic problems of thin plate. Katsikadelis [25] applied BEM in the analysis of plates in a wide range of engineering problems. Bèzine technique was applied by Guminiak and Sygulski to dynamic analysis of thin plates resting on internal kolumn suport [6]. Authors proposed modified boundary conditio and non-singular formulation of boundary integraf equation with elements of the constant type.

The present paper presents a simplified formulation for free vibration analysis of plates resting quasi at points located on the edges (on a small part of edges, along single boundary element). The modified formulation of boundary conditions and boundary integral equations was presented previously in [6]. According this formulation there is no need to introduce the equivalent shear forces at the boundary and concentrated forces at the plate corners.

\section{Integral formulation of thin plate vibration}

A free vibration problem of thin plate is considered. In each internal collocation point associated with single lumped mass there are introduced displacement vector

$$
w_{i}=W_{i} \cdot \sin \omega t
$$

acceleration vector

$$
\ddot{w}_{i}=-\omega^{2} \cdot W_{i} \sin \omega t
$$

and inertial force vector

$$
B_{i}=\omega^{2} \cdot m_{i} \cdot W_{i}
$$

where $\omega$ is the plates natural frequency.

On the plate boundary, there are considered following amplitudes of variables: shear force $\widetilde{T}_{n}$, bending moment $M_{n}$ and deflection $w$, angle of rotation in normal direction $\varphi_{n}$ and angle of rotation in tangent direction $\varphi_{s}$. The expression $\widetilde{T}_{n}(\mathbf{y})=T_{n}(\mathbf{y})+R_{n}(\mathbf{y})$ denotes shear force for clamped and for simply-supported edges [26]: 


$$
\widetilde{T}_{n}(\mathbf{y})=\left\{\begin{array}{l}
V_{n}(\mathbf{y}) \text { on the boundary far from the corner } \\
R_{n}(\mathbf{y}) \text { on a small fragment of the boundary close to the corner }
\end{array}\right.
$$

Because the relation between $\varphi_{s}(\mathbf{y})$ and the deflection is known: $\varphi_{s}(\mathbf{y})=\frac{d w(\mathbf{y})}{d s}$ can be evaluated using a finite difference scheme of the deflection with two or more adjacent nodal values. In this analysis, the employed finite difference scheme includes the deflections of two adjacent nodes. The boundary integral equations are derived using Bettie theorem. Two plates are considered: infinite plate, subjected unit concentrated loading and the real one. As a result, the first boundary integral equation is in the form:

$$
\begin{aligned}
& c(\mathbf{x}) \cdot w(\mathbf{x})+\int_{\Gamma}\left[T_{n}^{*}(\mathbf{y}, \mathbf{x}) \cdot w(\mathbf{y})-M_{n s}^{*}(\mathbf{y}, \mathbf{x}) \cdot \frac{d w(\mathbf{y})}{d s}-M_{n}^{*}(\mathbf{y}, \mathbf{x}) \cdot \varphi_{n}(\mathbf{y})\right] \cdot d \Gamma(\mathbf{y})= \\
& =\int_{\Gamma}\left[\widetilde{T}_{n}(\mathbf{y}) \cdot w^{*}(\mathbf{y}, \mathbf{x})-M_{n}(\mathbf{y}) \cdot \varphi_{n}^{*}(\mathbf{y}, \mathbf{x})\right] \cdot d \Gamma(\mathbf{y})+\sum_{i=1}^{I} B_{i} \cdot w^{*}(i, \mathbf{x})
\end{aligned}
$$

where the fundamental solution of biharmonic equation $\nabla^{4} w=(1 / D) \cdot \bar{\delta}(\mathbf{y}-\mathbf{x})$ is given as a Green function

$$
w^{*}(\mathbf{y}, \mathbf{x})=\frac{1}{8 \pi \cdot D} \cdot r^{2} \cdot \ln r
$$

for a thin isotropic plate, $r=|\mathbf{y}-\mathbf{x}|, \bar{\delta}$ is Dirac delta and $D=\left(E h_{\mathrm{p}}^{3}\right) /\left(12\left(1-v_{\mathrm{p}}^{2}\right)\right)$ is plate stiffness. The coefficient $c(\mathbf{x})$ depends on localization of point $\mathrm{x}$ and $c(\mathbf{x})=1$, when $\mathbf{x}$ is located inside the plate region, $c(\mathbf{x})=0.5$, when $\mathbf{x}$ is located on the smooth boundary and $c(\mathbf{x})=0$, when $\mathbf{x}$ is located outside the plate region.

The second boundary integral equation can be derived by substituting of unit concentrated force $P^{*}=1^{*}$ unit concentrated moment $M_{n}^{*}=1^{*}$. It is equivalent to differentiate the first boundary integral equation (5) on $n$ direction in point $\mathbf{x}$ on a plate boundary.

$$
\begin{aligned}
& c(\mathbf{x}) \cdot \varphi_{n}(\mathbf{x})+\int_{\Gamma}\left[\bar{T}_{n}^{*}(\mathbf{y}, \mathbf{x}) \cdot w(\mathbf{y})-\bar{M}_{n s}^{*}(\mathbf{y}, \mathbf{x}) \cdot \frac{d w(\mathbf{y})}{d s}-\bar{M}_{n}^{*}(\mathbf{y}, \mathbf{x}) \cdot \varphi_{n}(\mathbf{y})\right] \cdot d \Gamma(\mathbf{y})= \\
& =\int_{\Gamma}\left[\widetilde{T}_{n}(\mathbf{y}) \cdot \bar{w}^{*}(\mathbf{y}, \mathbf{x})-M_{n}(\mathbf{y}) \cdot \bar{\varphi}_{n}^{*}(\mathbf{y}, \mathbf{x})\right] \cdot d \Gamma(\mathbf{y})+\sum_{i=1}^{I} B_{i} \cdot \bar{w}^{*}(i, \mathbf{x})
\end{aligned}
$$


and

$$
\begin{aligned}
& \left\{\bar{T}_{n}^{*}(\mathbf{y}, \mathbf{x}), \bar{M}_{n}^{*}(\mathbf{y}, \mathbf{x}), \bar{M}_{n s}^{*}(\mathbf{y}, \mathbf{x}), \bar{w}^{*}(\mathbf{y}, \mathbf{x}), \bar{\varphi}_{n}^{*}(\mathbf{y}, \mathbf{x}), \bar{\varphi}_{s}^{*}(\mathbf{y}, \mathbf{x})\right\}= \\
& =\frac{\partial}{\partial n(\mathbf{x})}\left\{T_{n}^{*}(\mathbf{y}, \mathbf{x}), M_{n}^{*}(\mathbf{y}, \mathbf{x}), M_{n s}^{*}(\mathbf{y}, \mathbf{x}), w^{*}(\mathbf{y}, \mathbf{x}), \varphi_{n}^{*}(\mathbf{y}, \mathbf{x}), \varphi_{s}^{*}(\mathbf{y}, \mathbf{x})\right\}
\end{aligned}
$$

The second boundary integral equation can be also introduced by additional collocation point, which is located in the same normal line outside the plate edge. According this approach, the second equation has the same mathematical form as the first one (5). This double collocation point approach was presented in publication [14-17].

Idea of the proposed approach and formulation of boundary integral equation in plate bending is shown in the Figure 1.

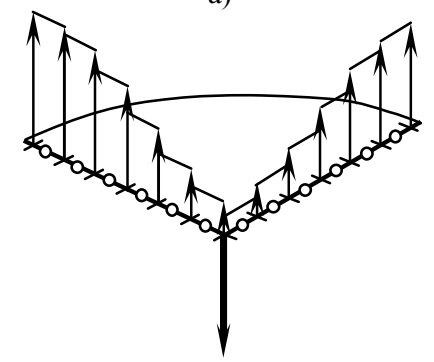

b)

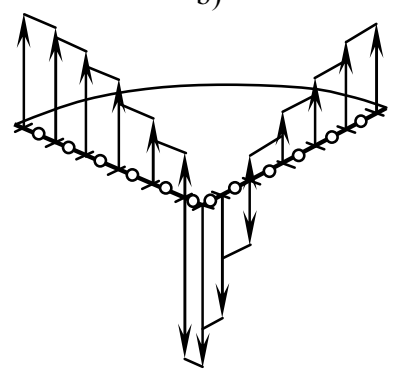

Fig. 1. Distribution of the support reaction - classic (a) and present (b) approach

\section{Definition of boundary support in the vicinity of the selected point}

Definition of boundary support in the vicinity of the selected point is shown in the Figure 2a.
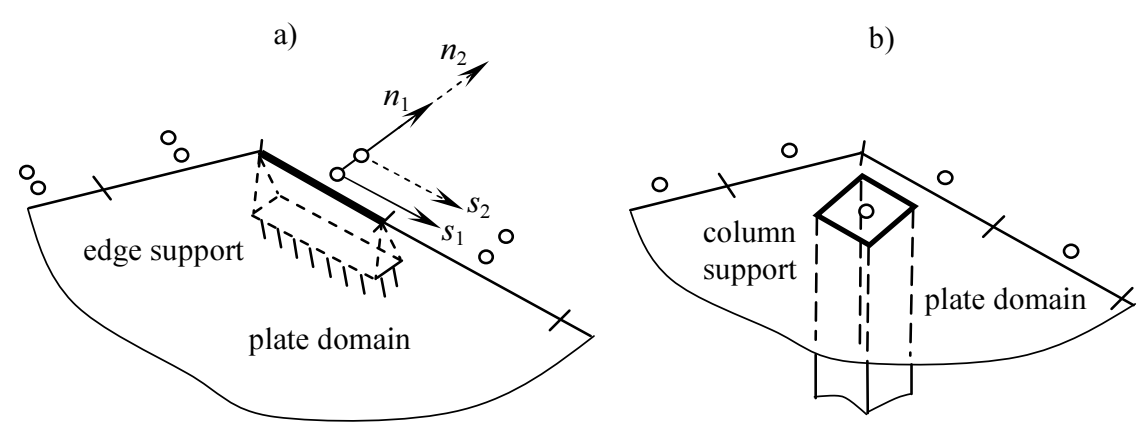

Fig. 2. Definition of boundary support in the vicinity of the selected point (a) and as a column support (b) 
The boundary condition is defined as follow:

$$
w=0, \varphi_{s}=0, \varphi_{n} \neq 0
$$

and the unknown boundary values are: shear force $T_{n}$ and $\varphi_{n}$, the angle of rotation in direction $n$. An alternative approach can be achieved if the column support will be introduced and located near the plate edge (Fig. 2b). The influence of column support localization on natural frequencies and modes is presented in [6].

\section{Construction of set of algebraic equation}

A plate edge is discretized using boundary elements. In matrix notation the set of algebraic equation has the form:

$$
\left[\begin{array}{cc}
\mathbf{G}_{\mathbf{B B}} & -\lambda \cdot \mathbf{G}_{\mathbf{B w}} \\
\mathbf{G}_{\mathbf{w B}} & -\lambda \cdot \mathbf{G}_{\mathbf{w w}} \cdot \mathbf{M}_{\mathrm{p}}+\mathbf{I}
\end{array}\right] \cdot\left\{\begin{array}{l}
\mathbf{B} \\
\mathbf{w}
\end{array}\right\}=\left\{\begin{array}{l}
\mathbf{0} \\
\mathbf{0}
\end{array}\right\}
$$

where $\mathbf{M}_{\mathrm{p}}=\operatorname{diag}\left(m_{1}, m_{2}, \ldots, m_{N}\right), \lambda=\omega^{2}, \mathbf{I}$ is the unit matrix and $N$ is the number of lumped masses. The elements of characteristic matrix: $\mathbf{G}_{\mathbf{B B}}$ and $\mathbf{G}_{\mathbf{w B}}$ contain integrals of suitable fundamental functions depended from type of boundary. These integrals are calculated in local coordinate system $n_{i}, s_{i}$ and then transformed to coordinate system $n_{k}, s_{k}[6]$. The quasi-diagonal integrals of characteristic matrix are calculated analytically and rest of them numerically, using 12-point Gauss quadrature. The second matrix equation in the set of equation (9) is obtained by construction of the boundary integral equations for internal collocation points. Elimination of boundary variables $\mathbf{B}$ from matrix equation (9) leads to a standard eigenvalue problem:

$$
\{\mathbf{A}-\tilde{\lambda} \cdot \mathbf{I}\} \cdot \mathbf{w}=\mathbf{0}
$$

where $\tilde{\lambda}=1 / \omega^{2}$ and

$$
\mathbf{A}=\left\{\mathbf{G}_{\mathbf{w w}} \cdot \mathbf{M}_{\mathrm{p}}-\mathbf{G}_{\mathbf{w B}} \cdot\left[\mathbf{G}_{\mathbf{B B}}\right]^{-1} \cdot \mathbf{G}_{\mathbf{B w}} \cdot \mathbf{M}_{\mathrm{p}}\right\}
$$

\section{Comparison of numerical results}

A square plate rested on the column supports and supported on boundary and skew plate supported on boundary are considered. The set of boundary elements of the constant type is regular. Each plate edge is divided by elements of the same 
length. The set of lumped masses is regular. The $i^{\text {th }}$ natural frequency is expressed in terms of parameter $\mu_{i}$ :

$$
\omega_{i}=\frac{\mu_{i}}{l^{2}} \cdot \sqrt{\frac{D}{\rho_{\mathrm{p}} \cdot h_{\mathrm{p}}}}
$$

where $\rho_{\mathrm{p}}$ is a plate density. Presented BEM results are obtained for: BEM I introduced one collocation point located outside the plate edge; BEM II - introduced two collocation points located outside the plate edge.

\subsection{A square plate rested on the column support and supported on boundary}

A square plate supported on boundary and rested on the column support is considered (Fig. 3). The results of calculation are verified using papers $[5,6]$. The column supports cross-section is assumed as square area with one collocation point with edge length $a$ [6]. The collocation points of boundary elements are located outside, near the plate edge. For one collocation point: $\varepsilon_{1}=\varepsilon=\delta / d=0.001$ [6] where $\delta$ is distance of collocation point from the plate edge and $d$ is the boundary element length. For two collocation points: $\varepsilon_{1}=0.001$ and $\varepsilon_{2}=0.01$. The column support dimensions are: $a / l=1 / 30$ [6]. The number of all boundary elements is equal to 120 and the number of lumped masses is equal 225. The number of boundary elements describing free edge is equal 116 and they form a set of elements of equal length. The length of single boundary element support is equal to $1 / 5$ of length of single elements describing free edge. Parameters $\mu_{i}$ are presented in Table 1 and the first six modes are shows in Figure 4.

a)

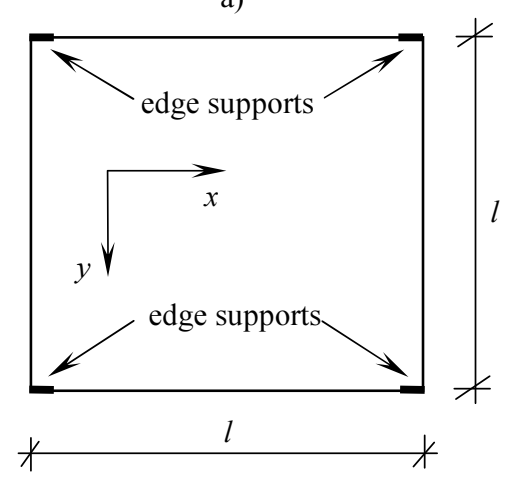

b)

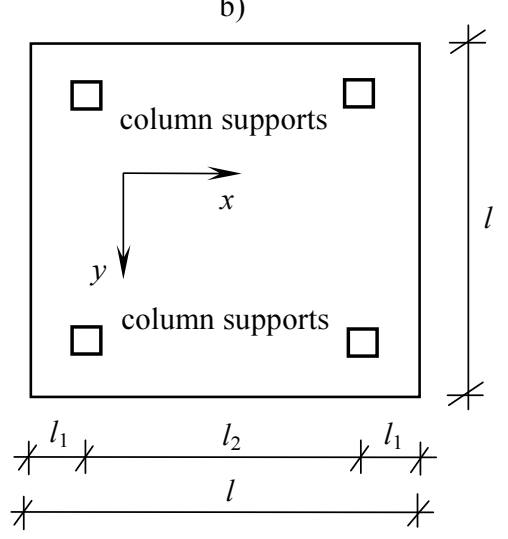

Fig. 3. A square plate: a) supported on boundary in the vicinity of the selected points, b) supported by the columns 
Table 1

Comparison of natural frequencies

\begin{tabular}{|c|c|c|c|c|c|c|}
\hline \multicolumn{7}{|c|}{$\mu_{i}$} \\
\hline Modes & 1 & 2 & 3 & 4 & 5 & 6 \\
\hline BEM I - present & 7.263 & 15.796 & 16.618 & 19.694 & 39.662 & 45.264 \\
\hline BEM II - present & 7.830 & 15.604 & 16.331 & 19.703 & 38.885 & 46.776 \\
\hline$l_{1} / l=0.00,[5]$ & 7.320 & 16.920 & 16.920 & 19.600 & - & - \\
\hline$l_{1} / l=0.05,[6]$ & 9.493 & 19.384 & 19.384 & 19.712 & 50.066 & 50.237 \\
\hline$l_{1} / l=0.05,[5]$ & 9.540 & 19.600 & 20.090 & 20.090 & - & - \\
\hline
\end{tabular}

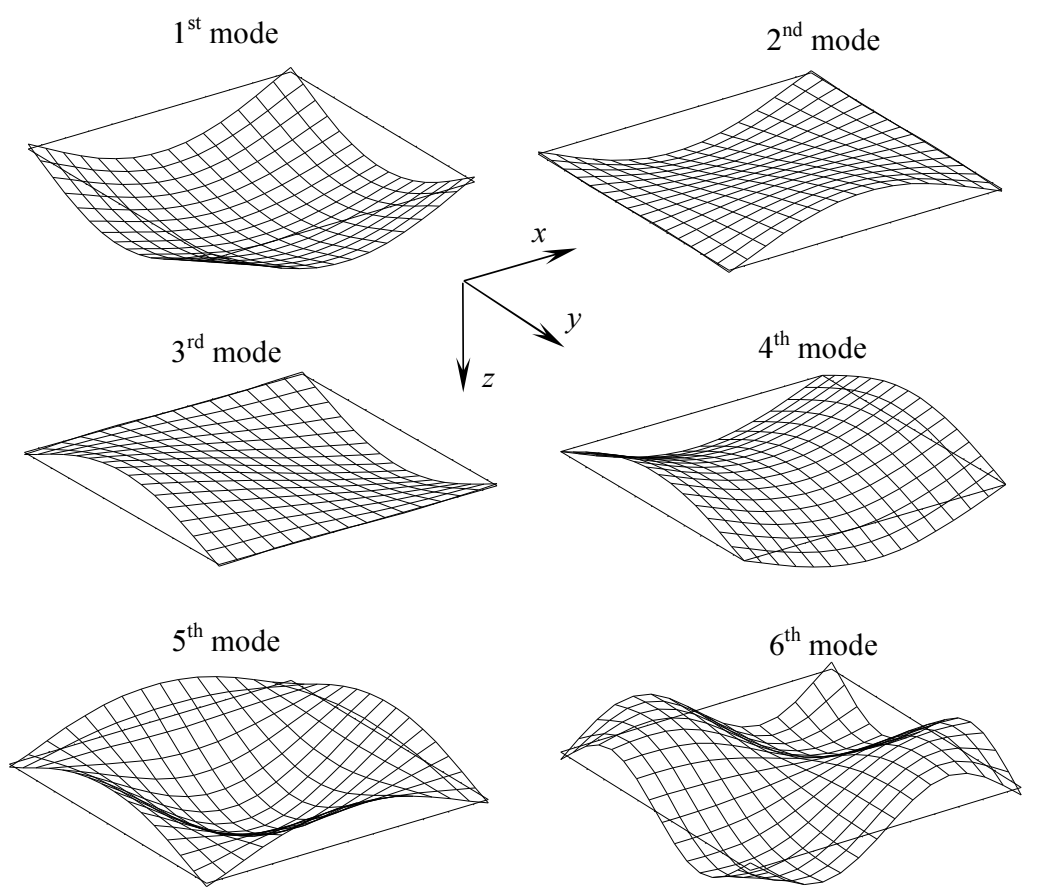

Fig. 4. First six modes of a square plate supported in the vicinity of the corners

\subsection{A skew plate supported on boundary}

A skew plate supported on boundary presented on Figure 5 is considered. The collocation points of boundary elements are located outside, near the plate edge. For one collocation point: $\varepsilon_{1}=\varepsilon=\delta / d=0.0015$ where $\delta$ is the distance of collocation point from the plate edge and $d$ is the boundary element length. For two collocation points: $\varepsilon_{1}=\varepsilon$ and $\varepsilon_{2}=0.015$. The number of all boundary elements is equal to 120 and the number of lumped masses is equal 100 . Number of boundary 
element describing free edge is equal 116. They form the set of elements of equal length along each edge. The length of single boundary element support is equal 1/5 of length of single element describing free edge along $x$ direction. Parameters $\mu_{i}$ are presented in Table 2 and the first six modes are show in Figure 6.

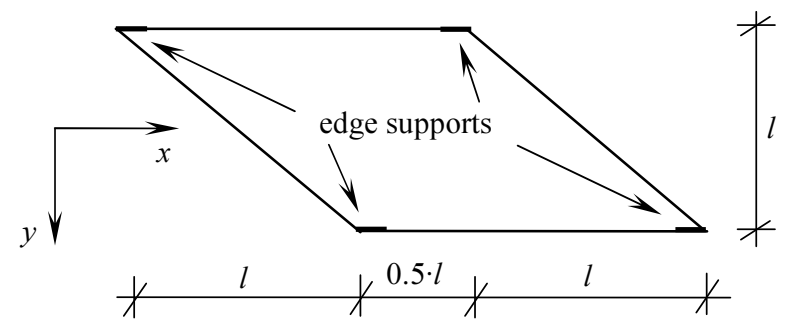

Fig. 5. A skew supported on boundary in the vicinity of the corners

Table 2

Comparison of natural frequencies

\begin{tabular}{|c|c|c|c|c|c|c|}
\hline \multicolumn{7}{|c|}{$\mu_{\mathrm{i}}$} \\
\hline Modes & 1 & 2 & 3 & 4 & 5 & 6 \\
\hline BEM I - present & 19.347 & 24.088 & 45.029 & 67.876 & 85.625 & 86.184 \\
\hline BEM II - present & 19.355 & 24.098 & 45.050 & 67.901 & 86.636 & 86.198 \\
\hline
\end{tabular}

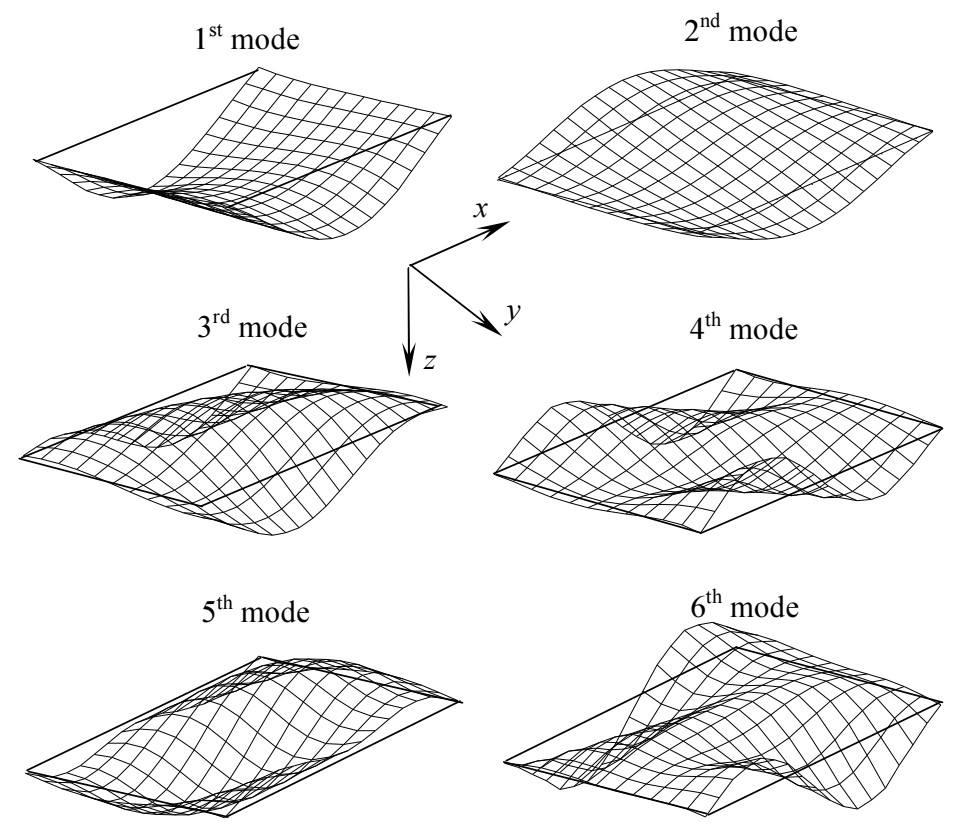

Fig. 6. First six modes of a skew plate supported at the corners 


\section{Conclusions}

In this paper a linear theory of free vibration analysis of thin plates has been presented. The BEM with modified, simplified formulation of boundary conditions was used as a numerical tool. In this formulation, there is no need to introduce the Kirchhoff forces at a plate corners and the equivalent shear forces at a plate boundary. The collocation version of boundary element method with constant elements and non-singular calculations of integrals were proposed. Formulation of boundary integral equation with one and two external collocation points is presented. Obtained BEM numerical results were compared with results taken from analytical and another BEM way $[5,6]$ and they indicate that BEM in presented approach could be useful in engineering analysis of plate vibration. The set of algebraic equation is constructed using Bèzine technique, which allows transform set of equation to standard eigenvalue problem. This approach is also called Domain Boundary Element Method (DBEM). Governing equations formulated according to DBEM can also be similarly formulated using Analog Equation Method (AEM). This approach was introduced by Katsikadelis [27] and applied by Nerantzaki and Katsikadelis [28] to dynamic analysis of plates with variable thickness.

\section{References}

[1] Nadai A., Über die Biegung durchlaufender Platten und der rechteckigen Platte mit freien Rändern, Zeitschritt für angewandte Mathematik und Mechanik 1922, 2.

[2] Iguchi S., Die Eigenschwingungen und Klangfiguren der vierseitig freien rechteckigen Platte, Ingenieur-Archiv 1953, 21, 5-6.

[3] Kączkowski Z., Orthotropic rectangular plates with free edges, Archives of Applied Mechanics 1955, 7(4), (in Polish).

[4] Timoshenko S., Woinowsky-Krieger S., Theory of plates and shells, Arkady, Warszawa 1962.

[5] Woźnica K., Vibration and bending of rectangular plates supported punctually (in Polish), PhD Thesis, Warsaw University of Technology, Faculty of Civil Engineering, 1978.

[6] Guminiak M., Sygulski R., The analysis of internally supported thin plates by the Boundary Element Method. Part 2 - Free vibration analysis, Foundations of Civil and Environmental Engineering, 9, Poznan University of Technology, 2007, 43-74.

[7] Brebbia C.A., Telles J.C.F., Wrobel L.C., Boundary Element Techniques, Theory and Applications in Engineering, Springer-Verlag, Berlin Heidelberg, New York, Tokyo 1984.

[8] Burczyński T., The Boundary Element Method in Mechanics, Technical-Scientific Publishing House, Warszawa 1995 (in Polish).

[9] Bèzine G., Boundary integral formulation for plate flexure with arbitrary boundary condition, Mechanics Research Communications 1978, 5(4), 197-206.

[10] Stern M., A general boundary integral formulation for the numerical solution of plate bending problems, Int. J. Solids Structures 1979, 15, 169-782.

[11] Vander Weeën F., Application of the boundary integral equation method to Reissner's plate model, Int. J. Num. Meth. Engng. 1982, 18, 1-10.

[12] Litewka B., Sygulski R., Application of the fundamental solutions by Ganowicz in a static analysis of Reissner's plates by the boundary element method, Engineering Analysis with Boundary Elements 2010, 34, 1072-1081. 
[13] Ganowicz R., Selected problems of theory of Reissner and three layer plates, Theoretical and Applied Mechanics 1966, 3-4, 55-95, (in Polish).

[14] Myślecki K., Approximate fundamental solutions of equilibrium equations for thin plates on an elastic foundation, Arch. Civ. Mech. Eng. 2004, 4, 1.

[15] Myślecki K., Metoda elementów brzegowych w statyce dźwigarów powierzchniowych, Oficyna Wydawnicza Politechniki Wrocławskiej, Wrocław 2004.

[16] Myślecki K., Oleńkiewicz J., Analiza częstości drgań własnych płyty cienkiej Metodą Elementów Brzegowych, Problemy naukowo-badawcze budownictwa, Wydawnictwo Politechniki Białostockiej, Białystok 2007, 2, 511-516.

[17] Oleńkiewicz J., Analiza drgań wybranych dźwigarów powierzchniowych metodą elementów brzegowych, Rozprawa doktorska, Politechnika Wrocławska, Instytut Inżynierii Lądowej, 2011.

[18] Bèzine G., A boundary integral equation method for plate flexure with condition inside the domain, Int. J. Num. Meth. Engng. 1981, 15, 1647-1657.

[19] de Paiva J.B., Venturini W.S., Boundary element algorithm for building floor slab analysis, International Conference of BETECH 85, Adelaide, Australia, Brebbia C.A., Noye B.J. (eds.), Computational Mechanics Publications 1985, 201-209.

[20] de Paiva J.B., Venturini W.S., Analysis of building structures considering plate-beam-column interactions, International Conference of BETECH 87, Rio de Janeiro, Brazil, Brebbia C.A., Venturini W.S. (eds.), Computational Mechanics Publications 1987, 209-219.

[21] Hartmann F., Zotemantel R., The direct boundary element method in plate bending, Int. J. Num. Meth. Engng. 1986, 23, 2049-2069.

[22] Abdel-Akher A., Hartley G.A., Evaluation of boundary integrals for plate bending. Int. J. Num. Meth. Engng. 1989, 28, 75-93.

[23] Katsikadelis J.T., Sapountzakis E.J., Zorba E.G., A BEM approach to static and dynamic analysis of plates, Computational Mechanics, 1990, 7(1), 31-42.

[24] Providakis C.P., Toungelis G., A D/BEM approach to the transient response analysis of elastoplastic plates, Engineering Computations, 1998, 5(4), 501-511.

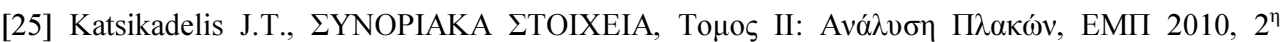

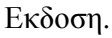

[26] Guminiak M., Litewka B., Selected problems of thin and thick plates theory in therms of BEM. Theoretical foundations and numerical comparison, Foundations of Civil and Environmental Engineering, 15, Poznan University of Technology, 2012, 41-90.

[27] Katsikadelis J.T., The analog equation method. A powerful BEM-based solution technique for solving linear and nonlinear engineering problems, [in:] C.A. Brebbia (ed.), Boundary Element Method XVI : Computational Mechanics Publications, Southampton 1994, 167-182.

[28] Nerantzaki M.S., Katsikadelis J.T., An analog equation solution to dynamic analysis of plates with variable thickness, Engineering Analysis with Boundary Elements, 1996, 17(2 Special Issue), 145-152. 